OPEN ACCESS

Edited by:

Learn-Han Lee,

Monash University Malaysia, Malaysia

Reviewed by:

Maryam Dadar,

Razi Vaccine and Serum Research

Institute, Iran

Hui-min Neoh

UKM Medical Molecular Biology Institute (UMBI), Malaysia

Wei Li Thong,

University of Manchester,

United Kingdom

*Correspondence:

Siew C. Ng

siewchienng@cuhk.edu.hk

Specialty section: This article was submitted to

Microbial Symbioses,

a section of the journal

Frontiers in Microbiology

Received: 20 February 2018 Accepted: 03 September 2018

Published: 25 September 2018

Citation:

Zuo T and Ng SC (2018) The Gut Microbiota in the Pathogenesis and

Therapeutics of Inflammatory Bowel

Disease. Front. Microbiol. 9:2247.

doi: 10.3389/fmicb.2018.02247

\section{The Gut Microbiota in the Pathogenesis and Therapeutics of Inflammatory Bowel Disease}

\author{
Tao Zuo ${ }^{1,2}$ and Siew C. $\mathrm{Ng}^{1,2 *}$ \\ ${ }^{1}$ Department of Medicine and Therapeutics, Institute of Digestive Disease, LKS Institute of Health Science, The Chinese \\ University of Hong Kong, Hong Kong, China, ${ }^{2}$ Faculty of Medicine, Center for Gut Microbiota Research, The Chinese \\ University of Hong Kong, Hong Kong, China
}

In the twenty first century, the changing epidemiology of inflammatory bowel disease (IBD) globally with increasing disease incidence across many countries relates to the altered gut microbiota, due to a combinatorial effect of environmental factors, human immune responses and genetics. IBD is a gastrointestinal disease associated with a gut microbial dysbiosis, including an expansion of facultative anaerobic bacteria of the family Enterobacteriaceae. Advances in high-throughput sequencing enable us to entangle the gut microbiota in human health and IBD beyond the gut bacterial microbiota, expanding insights into the mycobiota, virobiota and helminthes. Caudovirales (viruses) and Basidiomycota, Ascomycota, and Candida albicans (fungi) are revealed to be increased in IBD. The deconvolution of the gut microbiota in IBD lays the basis for unveiling the roles of these various gut microbiota components in IBD pathogenesis and being conductive to instructing on future IBD diagnosis and therapeutics. Here we comprehensively elucidate the alterations in the gut microbiota in IBD, discuss the effect of diets in the gut microbiota in relation to IBD, and illustrate the potential of manipulation of gut microbiota for IBD therapeutics. The therapeutic strategy of antibiotics, prebiotics, probiotics and fecal microbiota transplantation will benefit the effective application of precision microbiome manipulation in IBD.

Keywords: gut microbiota, bacteria, virobiota, mycobiota, helminths, diet, inflammatory bowel disease, fecal microbiota transplantation

\section{INTRODUCTION}

Inflammatory bowel diseases (IBD), including Crohn's disease (CD) and ulcerative disease (UC), are proposed to result from an inappropriate immune response to the gut microbes in a genetically susceptible host. It is a chronic inflammatory disorder of the intestinal tract of an unknown cause. The incidence of IBD has increased in the western world since the midst of the twentieth century (Molodecky et al., 2012; Rocchi et al., 2012; Hammer et al., 2016). At the turn of the twenty-first century, it plateaued in some developed nations with a prevalence of up to $0.5 \%$ of the general population, while it is continuing to rise in developing nations (Benchimol et al., 2009, 2014; Kaplan, 2015). Etiological studies on IBD have centered on several factors, including host genetics and immune responses, the gut microbiota, and the importance of environmental stimuli in disease 
pathogenesis (Figure 1). Gut dysbiosis has been consistently shown to be associated with IBD. Due to the expansion in application of high-throughput deep sequencing technology in the past decade, we are able to gradually unveiling the role of the microbiome in development of IBD. These findings have improved our knowledge on the functional mechanisms of the microbiome in the pathogenesis of IBD.

The gut microbiota, comprising bacteria, fungi, viruses, and other microorganisms, operate as a secondary organ system with critical functions to the host. IBD is amongst the most extensively studied of all inflammatory diseases that are closely associated with the gut microbiome. In this review, we discuss the role of the gut microbiota, including the bacterial microbiota, mycobiota and virobiota in the development of IBD as well as microbiotabased therapeutic approaches in the treatment of IBD.

\section{GUT MICROBIOME AND INFLAMMATORY BOWEL DISEASE (IBD)}

\section{Bacterial Microbiota}

Bacterial microbiota is the most well-studied component of the gut microbiota, which inhabit its host in variable concentrations. In the gastrointestinal (GI) tract, it reaches an upper level in the colon of $10^{11}$ or $10^{12}$ cells/g of luminal contents (Dave et al., 2012). It was estimated that our gut contains $\sim 1,000$ bacterial species and 100-fold more genes than that found in the human genome (Ley et al., 2006; Qin et al., 2010). This bacterial community performs a diversity of important functions in the host, including educating the immune system (Round and Mazmanian, 2009), secreting enzymes for digesting substrates inaccessible to the host (El Kaoutari et al., 2013), and repressing detrimental microorganisms (O'Hara and Shanahan, 2006). Overall, the phyla Firmicutes, Bacteroidetes, Actinobacteria and Verrucomicrobia are the predominant constituents in the healthy gut microbiota (Jandhyala et al., 2015). The gut bacterial microbiome exhibit differences with regard to both the mucosal-to-luminal and proximal-to-distal gradients, displaying substantial variations between individuals (Turnbaugh et al., 2009; Qin et al., 2010; Bäckhed et al., 2012). The gut bacterial microbiota develops from a low diverse community at birth into a highly complex community with the introduction of diets by 9-12 months of age (Koenig et al., 2011; Backhed et al., 2015). The microbiota becomes stable and resilient to environmental perturbations, such as dietary changes or short-term antibiotic exposure (Dethlefsen and Relman, 2011; Wu et al., 2011). A multitude of factors have been shown to intervene with the gut microbiome, including age, genetics, diet and drugs (Yatsunenko et al., 2012; Maier et al., 2018; Zuo et al., 2018).

Gut microbes were demonstrated to be an essential factor in intestinal inflammation in IBD (Tamboli et al., 2004; Sartor, 2008). Some studies suggest that dysbiosis occur in IBD (Frank et al., 2007; Casen et al., 2015; Putignani et al., 2016; Halfvarson et al., 2017), and a broad microbial alteration pattern was revealed including reduction in diversity, decreased abundances of bacterial taxa within the Phyla Firmicutes and Bacteroides, and increases in the Gammaproteobacteria (Table 1;
Frank et al., 2011; Morgan et al., 2012). In IBD, it has been consistently shown that there is a decrease in biodiversity, knowingly $\alpha$ diversity, and in species richness, a measure of the total number of species in a community. Patients with $\mathrm{CD}$ exhibited a reduced $\alpha$ diversity in the fecal microbiome, compared with healthy controls (Manichanh et al., 2006), and similar findings were found in monozygotic twins discordant for CD (Dicksved et al., 2008). This decreased diversity was partly linked to the temporal instability of the dominant taxa in IBD (Martinez et al., 2008). There is also reduced diversity in inflamed vs. non-inflamed tissues even within the same patient, and a lower bacterial load was observed at the inflamed regions in CD patients (Sepehri et al., 2007). A multicenter study that they investigated $>1,000$ treatmentnaïve pediatric $C D$ samples collected from multiple concurrent gastrointestinal locations (Gevers et al., 2014). They found that changes in bacteria, including increased Veillonellaceae, Pasteurellacaea, Enterobacteriaceae, and Fusobacteriaceae, and decreased Bacteroidales, Erysipelotrichales, and Clostridiales, strongly correlated with disease status. This study also showed that rectal mucosa-associated microbiome profiling offered a feasible biomarker for the diagnosis of CD at the early stage of disease.

Human studies have shown that abundance of specific bacteria taxa were altered in IBD (Table 1). Enterobacteriacae bacteria are augmented both in patients with IBD and in mice (Lupp et al., 2007). Escherichia coli, particularly adherent-invasive E. coli (AIEC) strains, were isolated from ileal CD biopsies (DarfeuilleMichaud et al., 2004) and were also found in UC patients (Sokol et al., 2006). Meanwhile, mucosal samples showed more pronounced enrichment than fecal samples (Chassaing and Darfeuille-Michaud, 2011). It indicates that the inflammatory environment in IBD may favor the growth of this bacterial clade, Enterobacteriaceae. Anti-inflammatory drug, mesalamine, could attenuate intestinal inflammation and decrease the abundance of Escherichia/Shigella in IBD (Benjamin et al., 2012; Morgan et al., 2012).

Fusobacteria is another clade of adherent and invasive bacteria. Bacteria of the genus Fusobacterium principally colonize both the oral cavity and the gut. Fusobacterium species were present at a higher abundance in the colonic mucosa of patients with UC compared to healthy controls (Ohkusa et al., 2002, 2009). When administered by rectal enema in mice, Fusobacterium varium was able to cause colonic mucosal inflammation (Ohkusa et al., 2003). The invasive ability of human Fusobacterium bacteria correlate positively with host IBD severity (Strauss et al., 2011), indicating that invasive Fusobacterium species may impact IBD pathology. Beyond that, Fusobacterium species were documented to be abundantly present in tumor than in adjacent normal tissue in colorectal cancer (Castellarin et al., 2012; Kostic et al., 2012; $\mathrm{Yu}$ et al., 2017). Besides, human Fusobacterium isolates were reported to have a tumorigenesis role in mice (Kostic et al., 2013).

There are also specific groups of gut bacteria that may play a protective role against IBD. A range of bacterial species, most notably the genera Lactobacillus, Bifidobacterium, and 

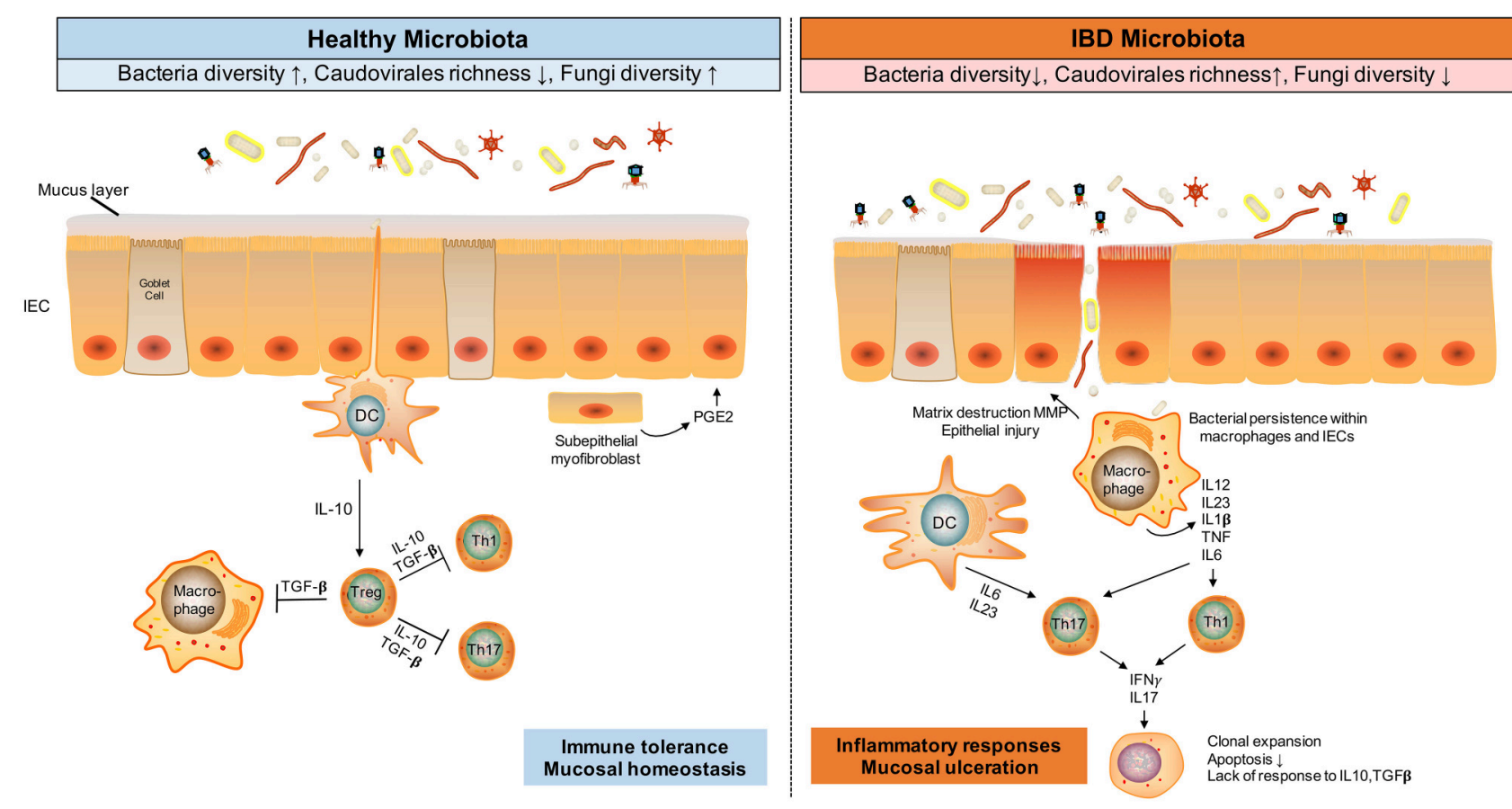

FIGURE 1 | Gut microbiota alteration and immune responses in IBD. The gut microbes, including bacteria, viruses and fungi, and dysfunctional immune responses, engaging Tregs, T-helper 1 (Th1), and Th17, are implicated in IBD pathogenesis. During homestasis, gut microbes induce an immune tolerance phenotype in the host, whilst in inflammatory conditions like IBD, antigens from dysbiotic microbes activate Th1 and Th17 cells, resulting in tissue injury, decreased mucus layer, and microbial penetration and persistence in the intestinal tissues. This mucosal injury results in further uptake of microbial antigens, TLR ligands, and viable organisms that perpetuate the immune responses. TGF, transforming growth factor; TGF, transforming growth factor; MMP, matrix metalloproteinase; DC, dendritic cell.

Faecalibacterium, have been shown to be protective of the host from mucosal inflammation via several mechanisms, including the stimulation of the anti-inflammatory cytokine (Sokol et al., 2008), including IL-10 and down-regulation of inflammatory cytokines (Llopis et al., 2009). Faecalibacterium prausnitzii, has been shown to have anti-inflammatory properties and was undererrepresented in IBD (Sokol et al., 2009). The abundance of $F$. prausnitzii is significantly decreased while the abundance of $E$. coli is increased in ileal biopsies of CD specimens (Willing et al., 2009). CD patients with low abundances of $F$. prausnitzii in the mucosa are more likely have relapse after surgery (Sokol et al., 2008). In contrast, restoration of F. prausnitzii after recurrence is associated with maintenance of clinical remission of UC (Varela et al., 2013). Epidemiological data in humans suggested a protective effect of Helicobacter pylori (H. pylori) infection against the development of autoimmune diseases, including IBD (Papamichael et al., 2014; Rokkas et al., 2015). Laboratory data demonstrated that $H$. pylori could induce immune tolerance and limit inflammatory responses (Arnold et al., 2011; Oertli and Müller, 2012; Oertli et al., 2012).

In chemically-induced mice with colitis, the colitis phenotype is more severe in germ-free mice than in conventionally reared mice (Kitajima et al., 2001). The commensal microbes protect the host via colonization resistance, where commensals occupy niches within the host and prevent invasion by pathogens (Callaway et al., 2008), outcompete pathogenic bacteria (Kamada et al., 2012). Commensals have also showed functional effects on pathogens, such as dampening virulence-related gene expression (Medellin-Pena et al., 2007). In addition, the gut microbiota can modulate the host mucosal immune response. Clostridium and Bacteroides species could induce the expansion of regulatory $\mathrm{T}$ cells (Treg) and to mitigate intestinal inflammation (Atarashi et al., 2013). Other gut bacterial members can alleviate mucosal inflammation by regulating NF- $\kappa$ B activation (Kelly et al., 2004).

Some members of the gut microbiota have the ability to ferment dietary fiber resulting in the production of shortchain fatty acids (SCFAs), including acetate, propionate, and butyrate. SCFAs have been shown to exert multiple beneficial effects on mammalian energy metabolism. They are the primary energy source for colonic epithelial cells (Ahmad et al., 2000) and can induce the expansion of colonic Treg cells (Atarashi et al., 2013; Smith et al., 2013). The butyrate-producing genus Faecalibacterium, which belonged to Ruminococcaceae, is decreased in IBD, especially in ileal CD (Sokol et al., 2008, 2009; Xenoulis et al., 2008; Kang et al., 2010; Morgan et al., 2012). Other SCFA-producing bacteria, Phascolarctobacterium and Roseburia are also reduced in CD, whilst Leuconostocaceae is depleted in UC (Morgan et al., 2012). The gut microbiota co-evolves with the polysaccharide-rich diet, to synergistically enable the host efficiently extract energy from dietary fiber and protect them from inflammation (Willing et al., 2009). Lack of dietary fiber intake has been associated with the development of IBD (Galvez 
TABLE 1 | Altered gut microbiota in IBD compared to healthy individuals in humans.

\begin{tabular}{lll}
\hline & Decreased in IBD & Increased in IBD \\
\hline Microbial & Bifidobacterium sp. & Proteobacteria \\
& Groups IV and XIVA Clostridium & Escherichia coli, \\
& Faecalibacterium prausnitzii & Fusobacterium species \\
& Roseburia species & Ruminococcus gnavusa \\
& Suterella species & Pasteurellaceae \\
& Bacteroides & Veillonellaceae \\
& Saccharomyces cerevisiae & Caudovirales \\
& Clavispora lusitaniae \\
& Kluyveromyces marxianus \\
& Candida albicans \\
& Candida tropicalis \\
& Cyberlindnera jadinii \\
Microbial & Auxotrophy \\
function & SCFAs, butyrate & Amino acid transport \\
& metabolism & Sulfate transport \\
Amino acid biosynthesis & Oxidative stress \\
& & Type Il secretion system \\
& Secretion of toxins \\
&
\end{tabular}

et al., 2005; Chiba et al., 2015; Pituch-Zdanowska et al., 2015). In addition, low fiber diet is associated with a low concentration of SCFAs (Galvez et al., 2005; Maslowski and Mackay, 2011).

\section{Fungal Microbiota (Mycobiota)}

Fungi represent only a minor constituent of the gut microbiota and account for $<0.1 \%$ of the total microbes (Qin et al., 2010). This may be an underestimation due to our current challenge to annotate fungi as a result of an incomplete fungal genomic database (Underhill and Iliev, 2014). Nevertheless, target region sequencing of marker genes, such as internal transcribed spacer (ITS) and $18 \mathrm{~S}$ rRNA, mapping to annotated databases has contributed to an improved understanding of the mycobiota in the gut (Qin et al., 2010).

Fungi vary in composition at different body sites in humans (Underhill and Iliev, 2014). The GI tract, urogenital tract and oral cavity have the largest proportion of the taxa of the Candida genus which comprises up to 160 species (Soll et al., 1991; Huffnagle and Noverr, 2013). Species-specific colonization patterns of Candida are observed in mammals. Candida albicans, C. parapsilosis and C. blabrata are common in humans whereas C. tropicalis predominates in mice (Underhill and Iliev, 2014). In contrary to the relative stability of the bacterial microbiota over time, the mouse gut mycobiota have been observed to vary over time among mouse reared in cages suggesting an environmental influence on the gut fungi (Dollive et al., 2013). Competition between gut bacteria and fungi was observed. In humans and mice, a relatively long-term use of antibiotics can promote fungal overgrowth and infection (Noverr et al., 2004; Dollive et al., 2013). In line with these findings, antibiotic-induced fungal overgrowth in the gut predispose the host to the development of allergic airway in response to mold spore exposures (Noverr et al., 2004). These observations support a role for the gut mycobiota in the development of immune-mediated diseases.
In healthy individuals, Saccharomyces, Candida, and Cladosporium were the most predominate genera (Hoffmann et al., 2013). Basidiomycota, Ascomycota, and C. albicans have been shown to be significantly elevated in IBD patients (Ott et al., 2008; Hoffmann et al., 2013; Sokol et al., 2017). However, until recently the fungi composition in the mucosa is beginning to be elucidated. Liguori et al. evaluated the gut fungal composition in patients with $\mathrm{CD}$ and healthy individuals (Liguori et al., 2016). Saccharomycetes and Tremellomycetes classes, which belong to the phyla Ascomycota and Basidiomycota, respectively, are the most abundant taxa in the mucosal samples from healthy individuals. At a lower taxonomic level, these two classes can be divided into the genera Candida, Debaryomyces, Saccharomyces, Malassezia, Sporobolomyces, Trichosporon, Wallemia, together with a smaller proportion of unidentified Filobasidiaceae and Xylariales, In samples from CD subjects, the genus Dioszegia and species Candida glabrata predominate especially during a disease flare whereas Trichosporon and Leptosphaeria genera are decreased (Mckenzie et al., 1990; Standaert-Vitse et al., 2009; Schwiertz et al., 2010; Hansen et al., 2013; Mukhopadhya et al., 2015; Liguori et al., 2016). In addition, Filobasidium uniguttulatum and Saccharomyces cerevisiae were significantly elevated in non-inflamed mucosa, whereas Xylariales were increased in inflamed mucosa of CD (Liguori et al., 2016). In contrast with CD patients, UC patients showed a relatively decreased diversity of fungi. This might be due to an impairment of the inhibition of antimicrobial peptides against bacteria in the small bowel and altered bile acid reabsorption which can benefit the growth of fungi in patients with CD and not in UC. Overall these preliminary data suggest that an increased fungal load of Candida species and altered bacteria diversity may be associated with the pathogenic feature of CD.

There is also emerging evidence favoring a role for the gut mycobiota in IBD pathogenesis. A number of studies have investigated host immune responses against fungal cell wall derived molecules (Levitz, 2010). The glycoprotein cell wall components of the fungi, chitin, $\beta$-glucans and mannans can trigger the innate immune response, through receptors, such as dectin-1 (a C-type lectin receptor), Toll-like receptors (TLR2 and TLR4), components of the complement system, and members of the scavenger receptor family (CD5, SCARF1, and CD36). Activation of these molecules leads to downstream immune cascades engaging molecules, such as CARD9, IL-17, IL-22, ITAM, NFAT, and NF- $\mathrm{B}$ (Sartor and $\mathrm{Wu}, 2017$ ). Colitis in mouse can be exacerbated due to infiltration of fungi through disrupted mucosal barrier. Brun et al. and Iliev et al. suggested that fungi can invade the host by breaking down the mucosal barrier (Brun et al., 2007; Underhill and Iliev, 2014). Intestinal epithelial cells (IECs) act as a physical barrier to prevent foreign pathogens from invading the host. However, in IBD in humans and mice, prolonged inflammation along with the disruption of tight junction (TJ) Occludin and ZO-1, leads to loss of integrity of IECs. Pathogens like fungi and bacteria can therefore penetrate the mucosal barrier and activate TLRs, Dectin-1 and CARD9 in the lamina propria resulting into a more severe inflammatory phenotype (Brun et al., 2007; Iliev et al., 2012). 


\section{Viral Microbiota (Virobiota)}

With the thriving of high-throughput sequencing technologies (Virgin, 2014), the importance of the gut virobiota is being better appreciated. The virobiota (which is referred to as the viral component of the microbiota) comprises both eukaryotic viruses and prokaryotic bacteriophages. They contain more diverse biological entities than the gut bacterial microbiota (Lecuit and Eloit, 2013; Ogilvie and Jones, 2015). The gut virome in healthy humans is characterized predominantly by the bacteriophages temperate dsDNA Caudovirales and ssDNA Microviridae that latently infect their bacterial hosts but can generate progenies that may infect and kill other bacteria when under stress (Reyes et al., 2010; Minot et al., 2012, 2013; Waller et al., 2014). In health, gut bacteriophages show intensive variation between subjects while temporally are stable in each individual (Reyes et al., 2010; Minot et al., 2013).

Bacteriophages are posited to play a role in IBD, though their function in disease pathogenesis remains unequivocal (PerezBrocal et al., 2013; Norman et al., 2015). Patients with CD exhibited a lower diversity but higher variability of the gut virome relative to controls (Perez-Brocal et al., 2013). The virome richness was increased in $\mathrm{CD}$ and UC patients from the United Kingdom, Chicago and Boston (Norman et al., 2015). Children with CD have more bacteriophages from the order Caudovirales in their tissues and intestinal washings compared to non-inflammatory controls (Wagner et al., 2013). Furthermore, Caudovirales virions have been obtained from washings of $\mathrm{CD}$ biopsies observed under electron microscopy (Lepage et al., 2008).

The expansion in bacteriophages in IBD could arise from commensal microbes entering lytic cycles or from new viruses introduction from the surrounding environment. Meanwhile, alteration in bacteriophage composition might have further impact on the bacterial microbiota ecology. Bacteriophages are shown to be primary drivers of bacterial fitness and diversity (Brüssow et al., 2004). Moreover, the gut microbiome is prone to be affected by bacteriophage invasion, resulting in changes in the bacterial abundance of specific species (Reyes et al., 2013). In the GI tract, bacteriophages engage in the horizontal transfer of genetic elements between bacterial populations, including those for antibiotic resistance and disease pathogenesis (Maiques et al., 2006; Zhang and LeJeune, 2008; Reyes et al., 2013). Hence, increased virome richness with widespread bacteriophage acquisition in IBD, potentially from external sources, could effectively change bacterial fitness. In mice, western diet could induce an expansion of Caudovirales (Kim and Bae, 2016), implicating a role for diet in altering the gut virome.

One potential role of enteric bacteriophages in IBD might be their direct interaction with the mammalian host. Bacteriophages can translocate from the GI lumen to systemic sites in murines (Górski et al., 2006), patients with CD and healthy controls (Parent and Wilson, 1971). They can also induce humoral immune responses (Uhr et al., 1962). Altogether, bacteriophages may act as immune ligands or antigens that boost host immunity and inflammation. On the other hand, some viruses, such as norovirus, can functionally replace the beneficial effect of commensal bacteria, ameliorating intestinal abnormalities in germ-free mice and diminishing susceptibility to intestinal damage caused by chemical injury and bacterial infection (Kernbauer et al., 2014). Beyond that, viruses attached to the mucosa could protect the epithelium against bacteria invasion, through binding interactions between Ig-Iike proteins exposed on the phage capsid and mucin glycoproteins on the mucosal surface (Barr J. et al., 2013; Barr J. J. et al., 2013).

There is also compelling evidence from mice showing that gut viruses play a causal role in chronic GI inflammation (Cadwell et al., 2010). Mice with a mutation in the gene ATG16L1 (an autophagy gene), which in humans predisposes to $\mathrm{CD}$, are developed without symptom. However, gut norovirus infection led to the manifestation of the disease, although solely harboring the susceptible allele or having the virus alone did not produce the disease, suggesting the combinatorial effect of susceptibility gene and virus in disease pathogenesis and/or progression. In a chemically induced colitis mouse model, the beneficial effect of the gut virome on the gut mucosal immune homeostasis was demonstrated (Yang et al., 2016). Mice, administered a cocktail of anti-viral drugs followed by dextran sulfate sodium (DSS), had more severe colitis than animals treated with DSS alone, along with greater reduction in colon length and weight loss. The observed protective effects of the gut viruses were mediated synergistically by TLR3 and TLR7, but not individually. In favor of this, patients carrying mutations in both TLR3 and TLR7 have been shown to have higher rates of hospitalization when compared with IBD patients without mutations (Yang et al., 2016).

\section{Helminths}

Gut helminthes are also considered to be one important gut microbial component coexisting in the gut with gut bacteria, fungi and viruses. The hygiene hypothesis suggests that a lack of early childhood exposure to symbiotic microorganisms and helminthic parasites increases susceptibility to immune mediated diseases in later life. Autoimmune and other immunologic diseases, such as IBD are highly prevalent in developed countries. However, with urbanization and environmental changes toward a more hygienic status, the uprising incidence of IBD appears to conincide with a diminished prevalence of helminth colonization in the host (Weinstock and Elliott, 2009).

Helminths are worm-like parasites, some of which have the potential to inhabit the GI tract and other regions of the body. Improvement in living standards in industrialized countries brings about environmental changes, which disrupt helminthic life cycles and lead to de-worming in humans. Before the twentieth century, every individual was likely to have at least one helminthic infection, mostly during early childhood, but this universal exposure has become rare in the twenty-first century (Elliott and Weinstock, 2012).

Helminths play an important immunoregulatory role in the host, and a lack of their presence has been associated with IBD development (Weinstock et al., 2002; Weinstock and Elliott, 2009; Ramanan et al., 2016). It was demonstrated by Ramanan et al. that helminths Trichuris muris and Heligmosoides polygyrus protected NOD2-deficient mice against intestinal inflammation, through inhibiting inflammatory Bacteroides 
species. This protective effect could be attributed to the functional influence of certain helminths on host physiology, exemplified by Trichinella spiralis (Motomura et al., 2009; Yang et al., 2014) and Schistosoma mansoni (Ruyssers et al., 2009) modulating Treg expansion, Trichuris trichiura (Broadhurst et al., 2010) upregulating Th22 response, and Heligmosomoides polygyrus (Elliott et al., 2008; Hang et al., 2013) down-regulating Th17 responses while expanding Treg population.

Compared with helminth-negative individuals, helminthcolonized subjects displayed higher gut bacterial diversity, in an indigenous Malaysian cohort (Lee et al., 2014). Orang Asli of the Temuan subtribe are helminthes-positive and they predominantly formed a cluster driven by the gut bacteria Faecalibacterium and Prevotella, compared with subjects in Kuala Lumpur (Ramanan et al., 2016). Those residing in the city in Kuala Lumpur clustered into another group characterized by Bacteroides (Ramanan et al., 2016). The concurrent disparity in helminth prevalence and microbiome configuration between rural and urban dwellers favors a linkage between helminth presence and bacterial microbiome structure, implicating a potential protective role for helminths in rural dwellers against IBD microbiota.

Helminth infections could cause increases in mucus and water secretion into the gut lumen, as measures for anti-inflammatory responses in the host (Stepek et al., 2002; Harnett and Harnett, 2006). In clinical trials of IBD, Trichiuris suis or pig whip worm were shown to be efficacious in patients with $\mathrm{CD}$ and $\mathrm{UC}$ (Summers et al., 2005a,b; Velthuis et al., 2010; Helmby, 2015).

\section{DIET AND THE GUT MICROBIOME}

Diet is among the most important factors influencing the gut microbiota (Albenberg and $\mathrm{Wu}, 2014$ ). Western diet is shown to predispose individuals to diseases including IBD, diabetes, obesity, hypercholesterolemia, and cardiovascular disease (Ley et al., 2008; Turnbaugh et al., 2008; Conlon and Bird, 2015; Agus et al., 2016; Carrillo-Larco et al., 2016). However, what or how certain diets protect against IBD is unclear, considering that urbanization is a significant risk factor for IBD (Soon et al., 2012). Study has shown that long-term diet can influence the composition and function of the gut microbiota (Muegge et al., 2011; Wu et al., 2011). Similarly, short-term diet can rapidly and reproducibly alter the gut microbiota (David et al., 2014). Compared to westerners on a western diet, inhabitants consuming a rural agrarian diet in rural areas and huntergatherers times showed a substantial higher diversity of the gut microbiota (De Filippo et al., 2010; Yatsunenko et al., 2012; Schnorr et al., 2014; Martínez et al., 2015; Obregon-Tito et al., 2015).

A western diet is associated with a decreased ratio of Bacteroides to Firmicutes and enhanced susceptibility to an increased presence of Adherent-Invasive E. coli (AIEC) infection (Agus et al., 2016). A recent review assessing the relationship between global IBD incidence and regional diets showed significant correlations between increased incidence of CD and increased consumptions of animal products, beer, honey, animal fats, and ghee, typical constituents of western diets. In contrast, an increased incidence of UC correlated with an increased consumption of pineapples and coffee products (Shivashankar et al., 2017). How these dietary products influence the gut microbiota and predispose individuals to IBD remains to be determined. Diet low in fiber was shown to be associated with a depletion of the microbial ecosystem in mice; this microbial extinction became irreversible and aggressive in the offspring over generations (Agus et al., 2016). The taxa driven to low abundances due to low-level intake of dietary microbiotaaccessible carbohydrates were inefficiently transferred to the progeny (El Kaoutari et al., 2013). Mice transplanted with microbiota from humans on a typical unrestricted American diet (AMER) responded incompletely to plant-rich, calorierestricted diet with optimized nutrient intake (CRON), while those transplanted with microbiota from CRON-consuming individuals responded strongly to both CRON and AMER diets (Griffin et al., 2017). These data imply that western diet may foster an irreversible microbial dysbiosis. In addition, a lowfiber diet was shown to exacerbate colitis and the expansion and activity of colonic mucus-degrading bacteria (Desai et al., 2016). Neither purified prebiotic fibers nor time-to-time diet oscillations between fiber-rich and fiber-deprived diet alleviate mucus layer degradation (Desai et al., 2016).

Specific types of diet are associated with alteration in the Prevotella to Bacteroides ratio. For instance, high consumption of amino acids, cholesterol, lipids and dairy products were shown to increase Bacteroides (Wu et al., 2011), while increase in Prevotella is boosted by consumption of sugar and other complex carbohydrates (De Filippo et al., 2010; Wu et al., 2011; Schnorr et al., 2014). The increased Alistipes and Bilophila were also linked to an animal-based diet (Wu et al., 2011; David et al., 2014). Vegans from non-westernized societies displayed an under-representation of Bifidobacterium (Wu et al., 2011), which might be ascribed to the absence of dairy products on their diet (Schnorr et al., 2014).

Diet has also been shown to impact on the gut mycobiota. In humans, increased Candida abundance is associated with diet high in carbohydrates, but not with diets high in protein, fatty acids and amino acids (Hoffmann et al., 2013). Consistently, in controlled feeding human study, Candida species in fecal samples were reduced in subjects consuming an animal-based diet and increased in subjects on a plant-based diet (David et al., 2014). The effects of diet on gut virobiota were also shown in humans and mice. In humans, dietary intervention was associated with a change in the virome to a new profile, in which individuals on the same diet converged (Minot et al., 2011). In mice, "western diet" could significantly enrich temperate bacteriophage Caudovriales both in the mucosa and luminal content (Kim and Bae, 2016). Interestingly, the community alteration of the virobiota occurred to a greater extent in the mucosa than in the lumen. Overall, diet has an impact on the gut mycobiota and virobiota. However, data and mechanistic study are still lacking, especially the associations among diet, mycobiota, virobiota and IBD.

Collectively, emerging animal and epidemiological studies have highlighted the necessity of preserving a diversified microbiome via diet. 


\section{MANIPULATION OF THE MICROBIOTA IN IBD THERAPEUTICS}

\section{Antibiotics, Probiotics and Prebiotics}

Antibiotics, probiotics and prebiotics have been utilized to treat IBD with varying results. Antibiotics have a modest effect in $\mathrm{CD}$ but data for probiotics and prebiotics are generally disappointing (Sartor and $\mathrm{Wu}, 2017$ ). Single antibiotics could ameliorate Crohn's colitis and septic complications, and prevent post-resection recurrence, but has not been shown to be effective in patients with UC. Combinations of antibiotics might improve outcomes (Ohkusa et al., 2010; Turner et al., 2014) but the longterm use of antibiotics may induce development of antibiotic resistance in gut microbes.

Traditional probiotics have demonstrated limited effect in treating UC, the probiotic combination VSL\#3 however (a probiotic preparation of eight live freeze-dried bacterial species, including Lactobacillus casei, L. delbrueckii subsp. Bulgaricus, L. acidophilus, L. plantarum, Bifidobacterium longum, B. infantis, $B$. breve, and Streptococcus salivarius subsp. Thermophiles; Bibiloni et al., 2005) and E. coli Nissle were shown to reduce active inflammation and sustain remission (Wehkamp et al., 2004; Schultz, 2008). Contrarily, they do not benefit patients with CD. F. prausnitzii may have a protective effect on the intestine by producing barrier-enhancing and immunosuppressive SCFAs, stimulating Tregs to produce IL-10 thereby inhibiting exaggerated immune responses in IBD. In multiple mouse models, F. prausnitzii, Clostridia strains, and B. fragilis could reduce the severity of colitis (Sokol et al., 2008; Round et al., 2011; Atarashi et al., 2013). These beneficial microbes and their metabolites should be explored as therapeutic agents in treatment of IBD. Although the idea of providing dietary substrates, such as oligosaccharides and fiber, as a prebiotic means to selectively increase the abundance of SCFA-producing commensals is tantalizing, results to date have been not satisfactory (Sartor and $\mathrm{Wu}, 2017)$. Alternatively, it is feasible to block AIEC epithelial adherence, invasion and translocation via use of antibodies to flagellin and of antagonists to glycopolymers or FimH (Yan et al., 2015; Chassaing et al., 2016). Blocking the protease activity of E. faecalis or protease receptor binding has been shown to inhibit mucosal permeability (Steck et al., 2011; Maharshak et al., 2015). Thus, selectively blocking the virulence products of pathogenic microbes or their activity may diminish the dysbiotic bacteria in the gut in IBD. Recently, it is shown that precision editing of the gut microbiota by tungstate ameliorates colitis in mice (Zhu et al., 2018). Tungstate treatment could prevent gut inflammation as well as the dysbiotic expansion of Enterobacteriaceae by selectively inhibitting molybdenumcofactor-dependent microbial respiratory pathways, while causing minimal changes in the microbiota composition under homeostatic conditions (Zhu et al., 2018).

Microbial markers have been shown to help in predicting which subset of patients are likely to have a positive response to treatment or who may undergo an aggressive disease course. Studies have shown that prognostic biomarkers from microbial profiling are instrumental to personalized therapy. For instance, microbial structure data, combined with level of apolipoprotein A1, can predict steroid-free remission in children newly diagnosed with CD (Haberman et al., 2014). Risk for post-operative recurrence of $\mathrm{CD}$ is linked to preoperative ileal concentrations of F. prausnitzii (Sokol et al., 2008). Risks for pouchitis post-colectomy in patients with UC can be predicted by the bacterial configuration (Machiels et al., 2017). In addition, microbial signatures correlate with response to therapy (Shaw et al., 2016) and dysbiosis is associated with relapse in patients after cessation of infliximab (Rajca et al., 2014).

There are a multitude of modern lifestyle associated factors that potentially associate with alterations of the gut microbiota (Table 2, any of these exposures may occur early in life). Studies from the West have shown that exposure of infants to antibiotics increases their risk for developing IBD (Patwa et al., 2011; Brito and Alm, 2016). More compelling evidence has been derived from human migration studies where migrants showed increased risks for IBD after migrating from developing to developed countries adopting an urbanized lifestyle (Probert et al., 1992; Barreiro-de Acosta et al., 2011). In a Canadian population-based inception and birth cohort study, rural residence in the first 1-5 years of life was associated with a lower risk of IBD (Benchimol et al., 2017). Early life colonization of microbes plays an essential role in the host immune system development (Gensollen et al., 2016). Further comprehensive appreciation of the underlying mechanisms would provide insights into the role of gut microbes in childhood in IBD pathogenesis.

\section{Fecal Microbiota Transplantation}

Fecal microbiota transplantation (FMT), a highly effective therapy for recurrent Clostridium difficile infection (CDI) (Kassam et al., 2013), has gained substantial interest as a novel treatment for inflammatory bowel disease (IBD). The success of FMT in treating CDI is ascribed to restoration of the gut microbial homeostasis in patients with dysbiosis (Khoruts and Sadowsky, 2016). This approach was later extended to studies of other diseases, such as IBD (Borody et al., 2003) and metabolic syndrome (Vrieze et al., 2013). The evidence for the efficacy of FMT in treating IBD is equivocal. A systematic analysis of 18 studies that included 122 patients with IBD found that around $36-45 \%$ of patients achieved clinical remission during follow-up (Colman and Rubin, 2014). Subgroup analyses demonstrated a pooled estimate of clinical remission rate of $22 \%$ for $\mathrm{UC}$ and $61 \%$ for CD (Colman and Rubin, 2014).

Two placebo-controlled trials of FMT on patients with UC have shown conflicting results with one study demonstrating the importance of the donor effect. It was documented that some patients with UC experienced fevers and increased levels of Creactive protein post-FMT (Angelberger et al., 2013). Disease flares in patients with UC or CD after FMT were also observed in the treatment of CDI (De Leon et al., 2013; Kelly et al., 2014a,b).

A recent multicenter, double-blind, randomized, placebocontrolled trial showed that intensive-dosing, with multidonor FMT induces clinical remission and endoscopic improvement in active ulcerative colitis and is associated with distinct microbial changes related to the outcome (Paramsothy et al., 2017). The primary outcome was achieved in 11 (27\%) of 41 patients 
TABLE 2 | Factors associated with modern lifestyle that is potentially associated with alterations of the gut microbiota.

\begin{tabular}{ll}
\hline Modern lifestyle & Often live in an urban setting, surrounded by \\
& concrete \\
Increased urbanization and migration to urban \\
areas \\
Birth in a hospital; increasing rate of cesarean \\
delivery \\
Small family size \\
Sanitation of living spaces: environment \\
colonized by resistant microorganisms \\
(including resistant bacteria, fungi, and acari) \\
Antibiotic usage early in life \\
Frequent body wash with hot water and soap \\
Low rate of Helicobacter pylori colonization \\
Decline in endemic parasitism \\
Food conserved by refrigeration \\
Consumption of processed foods and food \\
additives \\
Increased pollution in developing nations \\
\\
Vaginal delivery at home \\
Large family size, crowding \\
Livingin a rural setting in contact with soil \\
microorganisms \\
Ancestral colonization of the living environment \\
No antibiotics in infant life \\
Limited access to hot water and soap \\
High rate of Helicobacter pylori colonization \\
Parasitic worms common \\
Food conserved by microbial fermentation \\
Consumption of natural foods \\
\hline Traditional lifestyle
\end{tabular}

allocated to FMT compared with 3 (8\%) of 40 subjects who were assigned to placebo (risk ratio $3.6, p=0.021$ ). Importantly, the microbial diversity increased and persisted after FMT (Paramsothy et al., 2017). These data are consistent with a more recent study showing the low intensity pooled donor FMT is also effective in active UC (Costello et al., 2017).

It has been reported that $30-50 \%$ of the donor's bacterial microbiota persist in the recipient after FMT (Li et al., 2016). Two studies have shown bacteriophage transfer from donor to recipient (Chehoud et al., 2016; Zuo et al., 2017) and in a pilot study donor virome richness is associated with the efficacy of FMT (Zuo et al., 2017). When donor Caudovirales virome richness was higher than that of the recipient, the recipient was more likely to be cured after FMT treatment (Zuo et al., 2017). Patients with IBD have been shown to harbor significantly higher virome richness than healthy household controls (Norman et al.,

\section{REFERENCES}

Agus, A., Denizot, J., Thevenot, J., Martinez-Medina, M., Massier, S., Sauvanet, P., et al. (2016). Western diet induces a shift in microbiota composition enhancing susceptibility to Adherent-Invasive, E. coli infection and intestinal inflammation. Sci. Rep. 6:19032. doi: 10.1038/srep19032

Ahmad, M. S., Krishnan, S., Ramakrishna, B. S., Mathan, M., Pulimood, A. B., and Murthy, S. N. (2000). Butyrate and glucose metabolism by colonocytes in experimental colitis in mice. Gut 46, 493-499. doi: 10.1136/gut.46.4.493
2015), which may account for the higher failure rate of FMT in treating IBD than in treating CDI (De Leon et al., 2013; Colman and Rubin, 2014; Kelly et al., 2015). These data highlights the importance of donor selection, where inclusion of a donor with high virome richness or pooled multiple donors is preferred.

The long-term consequence of FMT in treating diseases remains unclear. In the future, FMT will be likely substituted by the use of defined microbial consortia. It was proven in animals that such an approach was feasible and effective for the treatment of IBD (Atarashi et al., 2013).

\section{PERSPECTIVES}

Efforts to date have effectively characterized the diverse constituents of the human gut microbiota in health and IBD. Bacterial microbiota is the most studied gut microbiota component though the function and strain-level resolution studies are still lacking. Beyond that, the under-studied gut microbiota components, viruses and fungi, and their interkingdom interactions with gut bacteria may have high impact in human health and IBD. These studies are still in its infancy. In summary, understanding the complexity of this gut ecosystem will require thorough mechanistic studies involving sophisticated molecular microbiologic techniques and animal studies to better define the role of different gut microbes in IBD pathogenesis and disease evolution. Precise interpretation of the cause and consequence of these microbial alterations will also require integration with host genetic polymorphisms and gene expression to allow proper comprehension of microbial-host interaction. Although microbe-based therapeutics is appealing, effective application of probiotics, prebiotics, antibiotics and FMT will require a personalized approach to identify defined subsets of patients that will benefit most from such a strategy.

\section{AUTHOR CONTRIBUTIONS}

TZ and SN devised the concept, acquired data, and wrote the manuscript.

\section{ACKNOWLEDGMENTS}

SN is supported by The Helmsley Charitable Trust through the ENIGMA study. SN and TZ are supported by a seed fund for Gut Microbiome Research provided by the Faculty of Medicine, The Chinese University of Hong Kong. 
pylori-induced gastric preneoplasia. Gastroenterology 140, 199-209. doi: 10.1053/j.gastro.2010.06.047

Atarashi, K., Tanoue, T., Oshima, K., Suda, W., Nagano, Y., Nishikawa, H., et al. (2013). T-reg induction by a rationally selected mixture of Clostridia strains from the human microbiota. Nature 500, 232-236. doi: 10.1038/nature12331

Bäckhed, F., Fraser, C. M., Ringel, Y., Sanders, M. E., Sartor, R. B., Sherman, P. M., et al. (2012). Defining a healthy human gut microbiome: current concepts, future directions, and clinical applications. Cell Host Microbe 12, 611-622. doi: 10.1016/j.chom.2012.10.012

Backhed, F., Roswall, J., Peng, Y., Feng, Q., Jia, H., Kovatcheva-Datchary, P., et al. (2015). Dynamics and stabilization of the human gut microbiome during the first year of life. Cell Host Microbe 17:852. doi: 10.1016/j.chom.2015.05.012

Barr, J., Auro, R., Furlan, M., Whiteson, K., Talago, N., Paul, L., et al. (2013). Bacteriophage adhered to mucus provide a novel mucosal immune system. J. Immunol. 190:61.8.

Barr, J. J., Auro, R., Furlan, M., Whiteson, K. L., Erb, M. L., Pogliano, J., et al. (2013). Bacteriophage adhering to mucus provide a non-host-derived immunity. Proc. Natl. Acad. Sci. U.S.A. 110, 10771-10776. doi: 10.1073/pnas.1305923110

Barreiro-de Acosta, M., Alvarez Castro, A., Souto, R., Iglesias, M., Lorenzo, A., and Dominguez-Munoz, J. E. (2011). Emigration to western industrialized countries: a risk factor for developing inflammatory bowel disease. J. Crohns Colitis 5, 566-569. doi: 10.1016/j.crohns,.2011.05.009

Benchimol, E. I., Guttmann, A., Griffiths, A. M., Rabeneck, L., Mack, D. R., Brill, H., et al. (2009). Increasing incidence of paediatric inflammatory bowel disease in Ontario, Canada: evidence from health administrative data. Gut 58, 1490-1497. doi: 10.1136/gut.2009.188383

Benchimol, E. I., Kaplan, G. G., Otley, A. R., Nguyen, G. C., Underwood, F. E., Guttmann, A., et al. (2017). Rural and urban residence during early life is associated with a lower risk of inflammatory bowel disease: a populationbased inception and birth cohort study. Am. J. Gastroenterol. 112, 1412-1422. doi: 10.1038/ajg.2017.208

Benchimol, E. I., Manuel, D. G., Guttmann, A., Nguyen, G. C., Mojaverian, N., Quach, P., et al. (2014). Changing age demographics of inflammatory bowel disease in ontario, canada: a population-based cohort study of epidemiology trends. Inflamm. Bowel Dis. 20, 1761-1769. doi: 10.1097/MIB.0000000000000103

Benjamin, J. L., Hedin, C. R., Koutsoumpas, A., Ng, S. C., McCarthy, N. E., Prescott, N. J., et al. (2012). Smokers with active Crohn's disease have a clinically relevant dysbiosis of the gastrointestinal microbiota. Inflamm. Bowel Dis. 18, 1092-1100. doi: 10.1002/ibd.21864

Bibiloni, R., Fedorak, R. N., Tannock, G. W., Madsen, K. L., Gionchetti, P., Campieri, M., et al. (2005). VSL\# 3 probiotic-mixture induces remission in patients with active ulcerative colitis. Am. J. Gastroenterol. 100, 1539-1546. doi: 10.1111/j.1572-0241.2005.41794.x

Borody, T. J., Warren, E. F., Leis, S., Surace, R., and Ashman, O. (2003). Treatment of ulcerative colitis using fecal bacteriotherapy. J. Clin. Gastroenterol. 37, 42-47. doi: 10.1097/00004836-200307000-00012

Brito, I. L., and Alm, E. J. (2016). Tracking strains in the microbiome: insights from metagenomics and models. Front. Microbiol. 7:712. doi: $10.3389 /$ fmicb.2016.00712

Broadhurst, M. J., Leung, J. M., Kashyap, V., McCune, J. M., Mahadevan, U., McKerrow, J. H., et al. (2010). IL-22(+) CD4(+) T Cells are associated with therapeutic trichuris trichiura infection in an ulcerative colitis patient. Sci. Transl. Med. 2:60ra88. doi: 10.1126/scitranslmed.3001500

Brun, P., Castagliuolo, I., Di Leo, V., Buda, A., Pinzani, M., Palù, G., et al. (2007). Increased intestinal permeability in obese mice: new evidence in the pathogenesis of nonalcoholic steatohepatitis. Am. J. Physiol. Gastr. L 292, G518-G525. doi: 10.1152/ajpgi.00024.2006

Brüssow, H., Canchaya, C., and Hardt, W. D. (2004). Phages and the evolution of bacterial pathogens: From genomic rearrangements to lysogenic conversion. Microbiol. Mol. Biol. R 68, 560-602. doi: 10.1128/MMBR.68.3.560-602.2004

Cadwell, K., Patel, K. K., Maloney, N. S., Liu, T. C., Ng, A. C., Storer, C. E., et al. (2010). Virus-plus-susceptibility gene interaction determines Crohn's disease gene Atg16L1 phenotypes in intestine. Cell 141, 1135-1145. doi: 10.1016/j.cell.2010.05.009

Callaway, T. R., Edrington, T. S., Anderson, R. C., Harvey, R. B., Genovese, K. J., Kennedy, C. N., et al. (2008). Probiotics, prebiotics and competitive exclusion for prophylaxis against bacterial disease. Anim. Health Res. Rev. 9, 217-225. doi: $10.1017 /$ S1466252308001540

Carrillo-Larco, R. M., Bernabé-Ortiz, A., Pillay, T. D., Gilman, R. H., Sanchez, J. F., Poterico, J. A., et al. (2016). Obesity risk in rural, urban and rural-to-urban migrants: prospective results of the PERU MIGRANT study. Int. J. Obes. 40, 181-185. doi: 10.1038/ijo.2015.140

Casen, C., Vebo, H. C., Sekelja, M., Hegge, F. T., Karlsson, M. K., Ciemniejewska, E., et al. (2015). Deviations in human gut microbiota: a novel diagnostic test for determining dysbiosis in patients with IBS or IBD. Aliment. Pharmacol. Ther. 42, 71-83. doi: 10.1111/apt.13236

Castellarin, M., Warren, R. L., Freeman, J. D., Dreolini, L., Krzywinski, M., Strauss, J., et al. (2012). Fusobacterium nucleatum infection is prevalent in human colorectal carcinoma. Genome Res. 22, 299-306. doi: 10.1101/gr.126516.111

Chassaing, B., and Darfeuille-Michaud, A. (2011). The commensal microbiota and enteropathogens in the pathogenesis of inflammatory bowel diseases. Gastroenterology 140, 1720-1728. doi: 10.1053/j.gastro.2011.01.054

Chassaing, B., Tran, H., and Gewirtz, A. (2016). O-007 Colitis vaccine: flagellin-elicited immunity keeps motile bacteria in check and protects against intestinal inflammation. Inflamm. Bowel Dis. 22:S3. doi: 10.1097/01.MIB.0000480045.11503.c5

Chehoud, C., Dryga, A., Hwang, Y., Nagy-Szakal, D., Hollister, E. B., Luna, R. A., et al. (2016). Transfer of viral communities between human individuals during fecal microbiota transplantation. mBio 7:e00322. doi: 10.1128/mBio.00322-16

Chiba, M., Tsuji, T., Nakane, K., and Komatsu, M. (2015). High amount of dietary fiber not harmful but favorable for Crohn disease. Perm. J. 19, 58-91. doi: 10.7812/TPP/14-124

Colman, R. J., and Rubin, D. T. (2014). Fecal microbiota transplantation as therapy for inflammatory bowel disease: a systematic review and meta-analysis. J. Crohns Colitis 8, 1569-1581. doi: 10.1016/j.crohns.2014.08.006

Conlon, M. A., and Bird, A. R. (2015). The impact of diet and lifestyle on gut microbiota and human health. Nutrients 7, 17-44. doi: 10.3390/nu7010017

Costello, S., Waters, O., Bryant, R., Katsikeros, R., Makanyanga, J., Schoeman, M., et al. (2017). Short duration, low intensity pooled faecal microbiota transplantation induces remission in patients with mild-moderately active ulcerative colitis: a randomised controlled trial. J. Crohns Colitis 11, S23. doi: 10.1093/ecco-jcc/jixx002.035

Darfeuille-Michaud, A., Boudeau, J., Bulois, P., Neut, C., Glasser, A. L., Barnich, N., et al. (2004). High prevalence of adherent-invasive Escherichia coli associated with ileal mucosa in Crohn's disease. Gastroenterology 127, 412-421. doi: 10.1053/j.gastro.2004.04.061

Dave, M., Higgins, P. D., Middha, S., and Rioux, K. P. (2012). The human gut microbiome: current knowledge, challenges, and future directions. Transl. Res. 160, 246-257. doi: 10.1016/j.trsl.2012.05.003

David, L. A., Maurice, C. F., Carmody, R. N., Gootenberg, D. B., Button, J. E., Wolfe, B. E., et al. (2014). Diet rapidly and reproducibly alters the human gut microbiome. Nature 505, 559-563. doi: 10.1038/nature12820

De Filippo, C., Cavalieri, D., Di Paola, M., Ramazzotti, M., Poullet, J. B., Massart, S., et al. (2010). Impact of diet in shaping gut microbiota revealed by a comparative study in children from Europe and rural Africa. Proc. Natl. Acad. Sci. U.S.A. 107, 14691-14696. doi: 10.1073/pnas.1005963107

De Leon, L. M., Watson, J. B., and Kelly, C. R. (2013). Transient flare of ulcerative colitis after fecal microbiota transplantation for recurrent clostridium difficile infection. Clin. Gastroenterol. Hepatol. 11, 1036-1038. doi: $10.1016 /$ j.cgh.2013.04.045

Desai, M. S., Seekatz, A. M., Koropatkin, N. M., Kamada, N., Hickey, C. A., Wolter, M., et al. (2016). A dietary fiber-deprived gut microbiota degrades the colonic mucus barrier and enhances pathogen susceptibility. Cell 167, 1339-1353.e21. doi: 10.1016/j.cell.2016.10.043

Dethlefsen, L., and Relman, D. A. (2011). Incomplete recovery and individualized responses of the human distal gut microbiota to repeated antibiotic perturbation. Proc. Natl. Acad. Sci. U.S.A. 108, 4554-4561. doi: 10.1073/pnas.1000087107

Dicksved, J., Halfvarson, J., Rosenquist, M., Järnerot, G., Tysk, C., Apajalahti, J., et al. (2008). Molecular analysis of the gut microbiota of identical twins with Crohn's disease. Isme J. 2, 716-727. doi: 10.1038/ismej.2008.37

Dollive, S., Chen, Y. Y., Grunberg, S., Bittinger, K., Hoffmann, C., Vandivier, L., et al. (2013). Fungi of the murine gut: episodic variation 
and proliferation during antibiotic treatment. PLoS ONE 8: 71806. doi: 10.1371/journal.pone.0071806

El Kaoutari, A., Armougom, F., Gordon, J. I., Raoult, D., and Henrissat, B. (2013). The abundance and variety of carbohydrate-active enzymes in the human gut microbiota. Nat. Rev. Microbiol. 11, 497-504. doi: 10.1038/nrmicro3050

Elliott, D. E., Metwali, A., Leung, J., Setiawan, T., Blum, A. M., Ince, M. N., et al. (2008). Colonization with Heligmosomoides polygyrus suppresses mucosal IL17 production. J. Immunol. 181, 2414-2419. doi: 10.4049/jimmunol.181.4.2414

Elliott, D. E., and Weinstock, J. V. (2012). Helminth-host immunological interactions: prevention and control of immune-mediated diseases. Ann. N. Y. Acad. Sci. 1247, 83-96. doi: 10.1111/j.1749-6632.2011.06292.x

Frank, D. N., Robertson, C. E., Hamm, C. M., Kpadeh, Z., Zhang, T., Chen, H., et al. (2011). Disease phenotype and genotype are associated with shifts in intestinalassociated microbiota in inflammatory bowel diseases. Inflamm. Bowel Dis. 17, 179-184. doi: 10.1002/ibd.21339

Frank, D. N., St Amand, A. L., Feldman, R. A., Boedeker, E. C., Harpaz, N., and Pace, N. R. (2007). Molecular-phylogenetic characterization of microbial community imbalances in human inflammatory bowel diseases. Proc. Natl. Acad. Sci. U.S.A. 104, 13780-13785. doi: 10.1073/pnas.0706625104

Galvez, J., Rodríguez-Cabezas, M. E., and Zarzuelo, A. (2005). Effects of dietary fiber on inflammatory bowel disease. Mol. Nutr. Food Res. 49, 601-608. doi: 10.1002/mnfr.200500013

Gensollen, T., Iyer, S. S., Kasper, D. L., and Blumberg, R. S. (2016). How colonization by microbiota in early life shapes the immune system. Science 352, 539-544. doi: 10.1126/science.aad9378

Gevers, D., Kugathasan, S., Denson, L. A., Vázquez-Baeza, Y., Van Treuren, W., Ren, B., et al. (2014). The treatment-naive microbiome in new-onset Crohn's disease. Cell Host Microbe 15, 382-392. doi: 10.1016/j.chom.2014.02.005

Górski, A., Wazna, E., Dabrowska, B. W., Dabrowska, K., Switala-Jelen, K., and Miedzybrodzki, R. (2006). Bacteriophage translocation. FEMS Immunol. Med. Mic. 46, 313-319. doi: 10.1111/j.1574-695X.2006.00044.x

Griffin, N. W., Ahern, P. P., Cheng, J., Heath, A. C., Ilkayeva, O., Newgard, C. B., et al. (2017). Prior dietary practices and connections to a human gut microbial metacommunity alter responses to diet interventions. Cell Host Microbe 21, 84-96. doi: 10.1016/j.chom.2016.12.006

Haberman, Y., Tickle, T. L., Dexheimer, P. J., Kim, M. O., Tang, D., Karns, R., et al. (2014). Pediatric Crohn disease patients exhibit specific ileal transcriptome and microbiome signature. J. Clin. Invest. 124, 3617-3633. doi: 10.1172/JCI75436

Halfvarson, J., Brislawn, C. J., Lamendella, R., Vázquez-Baeza, Y., Walters, W. A., Bramer, L. M., et al. (2017). Dynamics of the human gut microbiome in inflammatory bowel disease. Nat. Microbiol. 2:17004 doi: $10.1038 / \mathrm{nmicrobiol} .2017 .4$

Hammer, T., Nielsen, K. R., Munkholm, P., Burisch, J., and Lynge, E. (2016). The faroese IBD study: incidence of inflammatory bowel diseases across 54 years of population-based data. J. Crohns Colitis 10, 934-942. doi: 10.1093/ecco-jcc/jjw050

Hang, L., Blum, A. M., Setiawan, T., Urban, J. P., Stoyanoff, K. M., and Weinstock, J. V. (2013). Heligmosomoides polygyrus bakeri infection activates colonic Foxp3(+) T cells enhancing their capacity to prevent colitis. J. Immunol. 191, 1927-1934. doi: 10.4049/jimmunol.1201457

Hansen, R., Mukhopadhya, I., Meharg, C., Russell, R., Berry, S., El-Omar, E., et al. (2013). The role of the fungal microbiota in the pathogenesis of de-novo paediatric inflammatory bowel disease using next generation sequencing. Gut 62, A32. doi: 10.1136/gutjnl-2013-304907.073

Harnett, W., and Harnett, M. M. (2006). Filarial nematode secreted product ES-62 is an anti-inflammatory agent: therapeutic potential of small molecule derivatives and ES-62 peptide mimetics. Clin. Exp. Pharmacol. Physiol. 33, 511-518. doi: 10.1111/j.1440-1681.2006.04400.x

Helmby, H. (2015). Human helminth therapy to treat inflammatory disorderswhere do we stand? BMC Immunol. 16:12. doi: 10.1186/s12865-015-0074-3

Hoffmann, C., Dollive, S., Grunberg, S., Chen, J., Li, H. Z., Wu, G. D., et al. (2013). Archaea and fungi of the human gut microbiome: correlations with diet and bacterial residents. PLoS ONE 8:e66019. doi: 10.1371/journal.pone.0066019

Huffnagle, G. B., and Noverr, M. C. (2013). The emerging world of the fungal microbiome. Trends Microbiol. 21, 334-341. doi: 10.1016/j.tim.2013. 04.002

Iliev, I. D., Funari, V. A., Taylor, K. D., Nguyen, Q., Reyes, C. N., Strom, S. P., et al. (2012). Interactions between commensal fungi and the C-type lectin receptor dectin-1 influence colitis. Science 336, 1314-1317. doi: 10.1126/science.1221789
Jandhyala, S. M., Talukdar, R., Subramanyam, C., Vuyyuru, H., Sasikala, M., and Nageshwar Reddy, D. (2015). Role of the normal gut microbiota. World J. Gastroenterol. 21, 8787-8803. doi: 10.3748/wjg.v21.i29.8787

Kamada, N., Chen, G., and Núñez, G. (2012). A complex microworld in the gut: harnessing pathogen-commensal relations. Nat. Med. 18, 1190-1191. doi: $10.1038 / \mathrm{nm} .2900$

Kang, S., Denman, S. E., Morrison, M., Yu, Z., Dore, J., Leclerc, M., et al. (2010). Dysbiosis of fecal microbiota in Crohn's disease patients as revealed by a custom phylogenetic microarray. Inflamm. Bowel Dis. 16, 2034-2042. doi: 10.1002/ibd.21319

Kaplan, G. G. (2015). The global burden of IBD: from 2015 to 2025. Nat. Rev. Gastro. Hepat. 12, 720-727. doi: 10.1038/nrgastro.2015.150

Kassam, Z., Lee, C. H., Yuan, Y., and Hunt, R. H. (2013). Fecal microbiota transplantation for Clostridium difficile infection: systematic review and metaanalysis. Am. J. Gastroenterol. 108, 500-508. doi: 10.1038/ajg.2013.59

Kelly, C. R., Ihunnah, C., Fischer, M., Khoruts, A., Surawicz, C., Afzali, A., et al. (2014b). Fecal microbiota transplant for treatment of clostridium difficile infection in immunocompromised patients. Am. J. Gastroenterol. 109, 1065-1071. doi: 10.1038/ajg.2014.133

Kelly, C. R., Kahn, S. A., and Kashyap, P. (2015). Update on fecal microbiota transplantation 2015: indications, methodologies, mechanisms, and outlook (vol 149, pg 223, 2015). Gastroenterology 149, 1644-1644. doi: 10.1053/j.gastro.2015.05.008

Kelly, C. R., Ziud, H., and Kahn, S. (2014a). New diagnosis of Crohn's colits 6 weeks after fecal microbiota transplantation. Inflamm. Bowel Dis. 20:S21. doi: 10.1097/01.MIB.0000456762.32133.2e

Kelly, D., Campbell, J. I., King, T. P., Grant, G., Jansson, E. A., Coutts, A. G., et al. (2004). Commensal anaerobic gut bacteria attenuate inflammation by regulating nuclear-cytoplasmic shuttling of PPAR-[gamma] and RelA. Nat. Immunol. 5, 104-112. doi: 10.1038/ni1018

Kernbauer, E., Ding, Y., and Cadwell, K. (2014). An enteric virus can replace the beneficial function of commensal bacteria. Nature 516, 94-98. doi: 10.1038 /nature 13960

Khoruts, A., and Sadowsky, M. J. (2016). Understanding the mechanisms of faecal microbiota transplantation. Nat. Rev. Gastro. Hepat. 13, 508-516. doi: $10.1038 /$ nrgastro.2016.98

Kim, M. S., and Bae, J. W. (2016). Spatial disturbances in altered mucosal and luminal gut viromes of diet-induced obese mice. Environ. Microbiol. 18, 1498-1510. doi: 10.1111/1462-2920.13182

Kitajima, S., Morimoto, M., Sagara, E., Shimizu, C., and Ikeda, Y. (2001). Dextran sodium sulfate-induced colitis in germ-free IQI/Jic mice. Exp. Anim. Tokyo 50, 387-395. doi: 10.1538/expanim.50.387

Koenig, J. E., Spor, A., Scalfone, N., Fricker, A. D., Stombaugh, J., Knight, R., et al. (2011). Succession of microbial consortia in the developing infant gut microbiome. Proc. Natl. Acad. Sci. U.S.A. 108, 4578-4585. doi: 10.1073/pnas.1000081107

Kostic, A. D., Chun, E., Robertson, L., Glickman, J. N., Gallini, C. A., Michaud, M., et al. (2013). Fusobacterium nucleatum potentiates intestinal tumorigenesis and modulates the tumor-immune microenvironment. Cell Host Microbe 14, 207-215. doi: 10.1016/j.chom.2013.07.007

Kostic, A. D., Gevers, D., Pedamallu, C. S., Michaud, M., Duke, F., Earl, A. M., et al. (2012). Genomic analysis identifies association of Fusobacterium with colorectal carcinoma. Genome Res. 22, 292-298. doi: 10.1101/gr.126573.111

Lecuit, M., and Eloit, M. (2013). The human virome: new tools and concepts. Trends Microbiol. 21, 510-515. doi: 10.1016/j.tim.2013.07.001

Lee, S. C., Tang, M. S., Lim, Y. A., Choy, S. H., Kurtz, Z. D., Cox, L. M., et al. (2014). Helminth colonization is associated with increased diversity of the gut microbiota. PLoS Negl. Trop. Dis. 8:e2880. doi: 10.1371/journal.pntd.0002880

Lepage, P., Colombet, J., Marteau, P., Sime-Ngando, T., Doré, J., and Leclerc, M., (2008). Dysbiosis in inflammatory bowel disease: a role for bacteriophages? Gut 57, 424-425. doi: 10.1136/gut.2007.134668

Levitz, S. M. (2010). Innate recognition of fungal cell walls. PLoS Pathog. 6:1000758. doi: 10.1371/journal.ppat.1000758

Ley, R. E., Hamady, M., Lozupone, C., Turnbaugh, P. J., Ramey, R. R., Bircher, J. S., et al. (2008). Evolution of mammals and their gut microbes. Science 320, 1647-1651. doi: 10.1126/science. 1155725

Ley, R. E., Peterson, D. A., and Gordon, J. I. (2006). Ecological and evolutionary forces shaping microbial diversity in the human intestine. Cell 124, 837-848. doi: 10.1016/j.cell.2006.02.017 
Li, S. S., Zhu, A., Benes, V., Costea, P. I., Hercog, R., Hildebrand, F., et al. (2016). Durable coexistence of donor and recipient strains after fecal microbiota transplantation. Science 352, 586-589. doi: 10.1126/science.aad8852

Liguori, G., Lamas, B., Richard, M. L., Brandi, G., da Costa, G., Hoffmann, T. W., et al. (2016). Fungal dysbiosis in mucosa-associated microbiota of Crohn's disease patients. J. Crohns Colitis 10, 296-305. doi: 10.1093/ecco-jcc/jjv209

Llopis, M., Antolin, M., Carol, M., Borruel, N., Casellas, F., Martinez, C., et al. (2009). Lactobacillus casei downregulates commensals' inflammatory signals in Crohn's disease mucosa. Inflamm. Bowel Dis. 15, 275-283. doi: 10.1002/ibd.20736

Lupp, C., Robertson, M. L., Wickham, M. E., Sekirov, I., Champion, O. L., Gaynor, E. C., et al. (2007). Host-mediated inflammation disrupts the intestinal microbiota and promotes the overgrowth of Enterobacteriaceae. Cell Host Microbe 2, 119-129. doi: 10.1016/j.chom.2007.06.010

Machiels, K., Sabino, J., Vandermosten, L., Joossens, M., Arijs, I., de Bruyn, M., et al. (2017). Specific members of the predominant gut microbiota predict pouchitis following colectomy and IPAA in UC. Gut 66, 79-88. doi: 10.1136/gutjnl-2015-309398

Maharshak, N., Huh, E. Y., Paiboonrungruang, C., Shanahan, M., Thurlow, L., Herzog, J., et al. (2015). Enterococcus faecalis gelatinase mediates intestinal permeability via protease-activated receptor 2. Infect. Immun. 83, 2762-2770. doi: 10.1128/IAI.00425-15

Maier, L., Pruteanu, M., Kuhn, M., Zeller, G., Telzerow, A., Anderson, E. E., et al. (2018). Extensive impact of non-antibiotic drugs on human gut bacteria. Nature 555, 623-628. doi: 10.1038/nature25979

Maiques, E., Ubeda, C., Campoy, S., Salvador, N., Lasa, I., Novick, R. P., et al. (2006). Beta-lactam antibiotics induce the SOS response and horizontal transfer of virulence factors in Staphylococcus aureus. J. Bacteriol. 188, 2726-2729. doi: 10.1128/JB.188.7.2726-2729.2006

Manichanh, C., Rigottier-Gois, L., Bonnaud, E., Gloux, K., Pelletier, E., Frangeul, L., et al. (2006). Reduced diversity of faecal microbiota in Crohn's disease revealed by a metagenomic approach. Gut 55, 205-211. doi: 10.1136/gut.2005.073817

Martinez, C., Antolin, M., Santos, J., Torrejon, A., Casellas, F., Borruel, N., et al. (2008). Unstable composition of the fecal microbiota in ulcerative colitis during clinical remission. Am. J. Gastroenterol. 103, 643-648. doi: 10.1111/j.1572-0241.2007.01592.x

Martínez, I., Stegen, J. C., Maldonado-Gomez, M. X., Eren, A. M., Siba, P. M., Greenhill, A. R., et al. (2015). The gut microbiota of rural papua new guineans: composition, diversity patterns, and ecological processes. Cell Rep. 11, 527-538. doi: 10.1016/j.celrep.2015.03.049

Maslowski, K. M., and Mackay, C. R. (2011). Diet, gut microbiota and immune responses. Nat. Immunol. 12, 5-9. doi: 10.1038/ni0111-5

Mckenzie, H., Main, J., Pennington, C. R., and Parratt, D. (1990). Antibody to selected strains of saccharomyces-cerevisiae (Bakers and BrewersYeast) and Candida-Albicans in Crohns-disease. Gut 31, 536-538. doi: 10.1136/gut.31.5.536

Medellin-Pena, M. J., Wang, H. F., Johnson, R., Anand, S., and Griffiths, M. W. (2007). Probiotics affect virulence-related gene expression in Escherichia coli O157: H7. Appl. Environ. Microb. 73, 4259-4267. doi: 10.1128/AEM.00159-07

Minot, S., Bryson, A., Chehoud, C., Wu, G. D., Lewis, J. D., and Bushman, F. D. (2013). Rapid evolution of the human gut virome. Proc. Natl. Acad. Sci. U.S.A. 110, 12450-12455. doi: 10.1073/pnas. 1300833110

Minot, S., Grunberg, S., Wu, G. D., Lewis, J. D., and Bushman, F. D. (2012). Hypervariable loci in the human gut virome. Proc. Natl. Acad. Sci. U.S.A. 109, 3962-3966. doi: 10.1073/pnas.1119061109

Minot, S., Sinha, R., Chen, J., Li, H. Z., Keilbaugh, S. A., Wu, G. D., et al. (2011). The human gut virome: inter-individual variation and dynamic response to diet. Genome Res. 21, 1616-1625. doi: 10.1101/gr.122705.111

Molodecky, N. A., Soon, I. S., Rabi, D. M., Ghali, W. A., Ferris, M., Chernoff, G., et al. (2012). Increasing incidence and prevalence of the inflammatory bowel diseases with time, based on systematic review. Gastroenterology 142, 46-54. doi: 10.1053/j.gastro.2011.10.001

Morgan, X. C., Tickle, T. L., Sokol, H., Gevers, D., Devaney, K. L., Ward, D. V., et al. (2012). Dysfunction of the intestinal microbiome in inflammatory bowel disease and treatment. Genome Biol. 13:R79. doi: 10.1186/gb-2012-13-9-r79

Motomura, Y., Wang, H., Deng, Y., El-Sharkawy, R. T., Verdu, E. F., and Khan, W. I. (2009). Helminth antigen-based strategy to ameliorate inflammation in an experimental model of colitis. Clin. Exp. Immunol. 155, 88-95. doi: 10.1111/j.1365-2249.2008.03805.x

Muegge, B. D., Kuczynski, J., Knights, D., Clemente, J. C., González, A., Fontana, L., et al. (2011). Diet drives convergence in gut microbiome functions across mammalian phylogeny and within humans. Science 332, 970-974. doi: 10.1126/science.1198719

Mukhopadhya, I., Hansen, R., Meharg, C., Thomson, J. M., Russell, R. K., Berry, S. H., et al. (2015). The fungal microbiota of de-novo paediatric inflammatory bowel disease. Microbes Infect. 17, 304-310. doi: 10.1016/j.micinf.2014.12.001

Norman, J. M., Handley, S. A., Baldridge, M. T., Droit, L., Liu, C. Y., Keller, B. C., et al. (2015). Disease-specific alterations in the enteric virome in inflammatory bowel disease. Cell 160, 447-460. doi: 10.1016/j.cell.2015.01.002

Noverr, M. C., Noggle, R. M., Toews, G. B., and Huffnagle, G. B. (2004). Role of antibiotics and fungal microbiota in driving pulmonary allergic responses. Infect. Immun. 72, 4996-5003. doi: 10.1128/IAI.72.9.4996-5003.2004

Obregon-Tito, A. J., Tito, R. Y., Metcalf, J., Sankaranarayanan, K., Clemente, J. C., Ursell, L. K., et al. (2015). Subsistence strategies in traditional societies distinguish gut microbiomes. Nat. Commun. 6:6505. doi: 10.1038/ncomms7505

Oertli, M., and Müller, A. (2012). Helicobacter pylori targets dendritic cells to induce immune tolerance, promote persistence and confer protection against allergic asthma. Gut Microbes 3, 566-571. doi: 10.4161/gmic. 21750

Oertli, M., Sundquist, M., Hitzler, I., Engler, D. B., Arnold, I. C., Reuter, S., et al. (2012). DC-derived IL-18 drives Treg differentiation, murine Helicobacter pylori-specific immune tolerance, and asthma protection. J. Clin. Invest. 122, 1082-1096. doi: 10.1172/JCI61029

Ogilvie, L. A., and Jones, B. V. (2015). The human gut virome: a multifaceted majority. Front. Microbiol. 6:918. doi: 10.3389/fmicb.2015.00918

O'Hara, A. M., and Shanahan, F. (2006). The gut flora as a forgotten organ. EMBO Rep. 7, 688-693. doi: 10.1038/sj.embor.7400731

Ohkusa, T., Kato, K., Terao, S., Chiba, T., Mabe, K., Murakami, K., et al. (2010). Newly developed antibiotic combination therapy for ulcerative colitis: a double-blind placebo-controlled multicenter trial. Am. J. Gastroenterol. 105, 1820-1829. doi: 10.1038/ajg.2010.84

Ohkusa, T., Okayasu, I., Ogihara, T., Morita, K., Ogawa, M., and Sato, N. (2003). Induction of experimental ulcerative colitis by Fusobacterium varium isolated from colonic mucosa of patients with ulcerative colitis. Gut 52, 79-83. doi: 10.1136/gut.52.1.79

Ohkusa, T., Sato, N., Ogihara, T., Morita, K., Ogawa, M., and Okayasu, I. (2002). Fusobacterium varium localized in the colonic mucosa of patients with ulcerative colitis stimulates species-specific antibody. J. Gastroenterol. Hepatol. 17, 849-853. doi: 10.1046/j.1440-1746.2002.02834.x

Ohkusa, T., Yoshida, T., Sato, N., Watanabe, S., Tajiri, H., and Okayasu, I. (2009). Commensal bacteria can enter colonic epithelial cells and induce proinflammatory cytokine secretion: a possible pathogenic mechanism of ulcerative colitis. J. Med. Microbiol. 58, 535-545. doi: 10.1099/jmm.0.005801-0

Ott, S. J., Kuhbacher, T., Musfeldt, M., Rosenstiel, P., Hellmig, S., Rehman, A., et al. (2008). Fungi and inflammatory bowel diseases: alterations of composition and diversity. Scand. J. Gastroentero. 43, 831-841. doi: 10.1080/00365520801935434

Papamichael, K., Konstantopoulos, P., and Mantzaris, G. J. (2014). Helicobacter pylori infection and inflammatory bowel disease: is there a link? World J. Gastroenterol. 20:6374. doi: 10.3748/wjg.v20.i21.6374

Paramsothy, S., Kamm, M. A., Kaakoush, N. O., Walsh, A. J., van den Bogaerde, J., Samuel, D., et al. (2017). Multidonor intensive faecal microbiota transplantation for active ulcerative colitis: a randomised placebo-controlled trial. Lancet 389, 1218-1228. doi: 10.1016/S0140-6736(17)30182-4

Parent, K., and Wilson, I. D. (1971). Mycobacteriophage in Crohn's disease. Gut 12, 1019-1020. doi: 10.1136/gut.12.12.1019

Patwa, L. G., Fan, T. J., Tchaptchet, S., Liu, Y., Lussier, Y. A., Sartor, R. B., et al. (2011). Chronic intestinal inflammation induces stress-response genes in commensal Escherichia coli. Gastroenterology 141, 1842-1851.e1-10. doi: 10.1053/j.gastro,.2011.06.064

Perez-Brocal, V., Garcia-Lopez, R., Vazquez-Castellanos, J. F., Nos, P., Beltran, B., Latorre, A., et al. (2013). Study of the viral and microbial communities associated with Crohn's disease: a metagenomic approach. Clin. Transl. Gastroen. 4:e36. doi: 10.1038/ctg.2013.9

Pituch-Zdanowska, A., Banaszkiewicz, A., and Albrecht, P. (2015). The role of dietary fibre in inflammatory bowel disease. Prz. Gastroenterol. 10, 135-141. doi: $10.5114 /$ pg. 2015.52753 
Probert, C. S., Jayanthi, V., Pinder, D., Wicks, A. C., and Mayberry, J. F. (1992). Epidemiologic-study of ulcerative proctocolitis in indian migrants and the indigenous population of leicestershire. Gut 33, 687-693. doi: $10.1136 /$ gut.33.5.687

Putignani, L., Del Chierico, F., Vernocchi, P., Cicala, M., Cucchiara, S., Dallapiccola, B., et al. (2016). Gut microbiota dysbiosis as risk and premorbid factors of IBD and IBS along the childhood-adulthood transition. Inflamm. Bowel Dis. 22, 487-504. doi: 10.1097/MIB.0000000000000602

Qin, J., Li, R., Raes, J., Arumugam, M., Burgdorf, K. S., Manichanh, C., et al. (2010). A human gut microbial gene catalog established by metagenomic sequencing. Nature 464, 59-65. doi: 10.1038/nature08821

Rajca, S., Grondin, V., Louis, E., Vernier-Massouille, G., Grimaud, J. C., Bouhnik, Y., et al. (2014). Alterations in the intestinal microbiome (Dysbiosis) as a predictor of relapse after infliximab withdrawal in Crohn's disease. Inflamm. Bowel Dis. 20, 978-986. doi: 10.1097/MIB.0000000000000036

Ramanan, D., Bowcutt, R., Lee, S. C., Tang, M. S., Kurtz, Z. D., Ding, Y., et al. (2016). Helminth infection promotes colonization resistance via type 2 immunity. Science 352, 608-612. doi: 10.1126/science.aaf3229

Reyes, A., Haynes, M., Hanson, N., Angly, F. E., Heath, A. C., Rohwer, F., et al. (2010). Viruses in the faecal microbiota of monozygotic twins and their mothers. Nature 466, 334-338. doi: 10.1038/nature09199

Reyes, A., Wu, M., McNulty, N. P., Rohwer, F. L., and Gordon, J. I. (2013). Gnotobiotic mouse model of phage-bacterial host dynamics in the human gut. Proc. Natl. Acad. Sci. U.S.A. 110, 20236-20241. doi: 10.1073/pnas.1319470110

Rocchi, A., Benchimol, E. I., Bernstein, C. N., Bitton, A., Feagan, B., Panaccione, R., et al. (2012). Inflammatory bowel disease: a Canadian burden of illness review. Can J. Gastroenterol. 26, 811-817. doi: 10.1155/2012/984575

Rokkas, T., Gisbert, J. P., Niv, Y., and O'morain, C. (2015). The association between Helicobacter pylori infection and inflammatory bowel disease based on meta-analysis. United Eur Gastroenterol. J. 3, 539-550. doi: $10.1177 / 2050640615580889$

Round, J. L., Lee, S. M., Li, J., Tran, G., Jabri, B., Chatila, T. A., et al. (2011). The tolllike receptor 2 pathway establishes colonization by a commensal of the human microbiota. Science 332, 974-977. doi: 10.1126/science.1206095

Round, J. L., and Mazmanian, S. K. (2009). The gut microbiota shapes intestinal immune responses during health and disease. Nat. Rev. Immunol. 9, 313-323. doi: 10.1038/nri2515

Ruyssers, N. E., De Winter, B. Y., De Man, J. G., Loukas, A., Pearson, M. S., Weinstock, J. V., et al. (2009). Therapeutic potential of helminth soluble proteins in TNBS-induced colitis in mice. Inflamm. Bowel Dis. 15, 491-500. doi: 10.1002/ibd.20787

Sartor, R. B. (2008). Microbial influences in inflammatory bowel diseases. Gastroenterology 134, 577-594. doi: 10.1053/j.gastro.2007.11.059

Sartor, R. B., and Wu, G. D. (2017). Roles for intestinal bacteria, viruses, and fungi in pathogenesis of inflammatory bowel diseases and therapeutic approaches. Gastroenterology 152, 327-339. doi: 10.1053/j.gastro.2016.10.012

Schnorr, S. L., Candela, M., Rampelli, S., Centanni, M., Consolandi, C., Basaglia, G., et al. (2014). Gut microbiome of the Hadza hunter-gatherers. Nat. Commun. 5:3654 doi: $10.1038 /$ ncomms4654

Schultz, M. (2008). Clinical use of E. coli Nissle 1917 in inflammatory bowel disease. Inflamm. Bowel Dis. 14, 1012-1018. doi: 10.1002/ibd.20377

Schwiertz, A., Jacobi, M., Frick, J., Markus, R., Rusch, K., and Kohler, H. (2010). Microbiota in pediatric inflammatory bowel disease. J. Pediatr. Gastroenterol. Nutri. 50, E105-E105. doi: 10.1016/j.jpeds.2010.02.046

Sepehri, S., Kotlowski, R., Bernstein, C. N., and Krause, D. O. (2007). Microbial diversity of inflamed and noninflamed gut biopsy tissues in inflammatory bowel disease. Inflamm. Bowel Dis. 13, 675-683. doi: 10.1002/ibd.20101

Shaw, K. A., Bertha, M., Hofmekler, T., Chopra, P., Vatanen, T., Srivatsa, A., et al. (2016). Dysbiosis, inflammation, and response to treatment: a longitudinal study of pediatric subjects with newly diagnosed inflammatory bowel disease. Genome Med. 8:75. doi: 10.1186/s13073-016-0331-y

Shivashankar, R., Beauvais, J. C., and Lewis, J. D. (2017). The relationship of regional diets with global incidence rates of inflammatory bowel disease. Gastroenterology 152, S975-S976. doi: 10.1016/S0016-5085(17)33306-1

Smith, P. M., Howitt, M. R., Panikov, N., Michaud, M., Gallini, C., Bohlooly-y, M., et al. (2013). The microbial metabolites, short-chain fatty acids, regulate colonic Treg cell homeostasis. Science 341, 569-573. doi: 10.1126/science. 1241165
Sokol, H., Leducq, V., Aschard, H., Pham, H. P., Jegou, S., Landman, C., et al. (2017). Fungal microbiota dysbiosis in IBD. Gut 66, 1039-1048. doi: 10.1136/gutjnl-2015-310746

Sokol, H., Lepage, P., Seksik, P., Dore, J., and Marteau, P. (2006). Temperature gradient gel electrophoresis of fecal $16 \mathrm{~S}$ rRNA reveals active Escherichia coli in the microbiota of patients with ulcerative colitis. J. Clin. Microbiol. 44, 3172-3177. doi: 10.1128/JCM.02600-05

Sokol, H., Pigneur, B., Watterlot, L., Lakhdari, O., Bermudez-Humaran, L. G., Gratadoux, J. J., et al. (2008). Faecalibacterium prausnitzii is an antiinflammatory commensal bacterium identified by gut microbiota analysis of Crohn disease patients. Proc. Natl. Acad. Sci. U.S.A. 105, 16731-16736. doi: 10.1073/pnas.0804812105

Sokol, H., Seksik, P., Furet, J. P., Firmesse, O., Nion-Larmurier, I., Beaugerie, L., et al. (2009). Low counts of Faecalibacterium prausnitzii in colitis microbiota. Inflamm. Bowel Dis. 15, 1183-1189. doi: 10.1002/ibd.20903

Soll, D. R., Galask, R., Schmid, J., Hanna, C., Mac, K., and Morrow, B. (1991). Genetic dissimilarity of commensal strains of candida spp carried in different anatomical locations of the same healthy women. J. Clin. Microbiol. 29, $1702-1710$.

Soon, S., Molodecky, N. A., Rabi, D. M., Ghali, W. A., Barkema, H. W., and Kaplan, G. G. (2012). The relationship between urban environment and the inflammatory bowel diseases: a systematic review and meta-analysis. BMC Gastroenterol. 12:51. doi: 10.1186/1471-230X-12-51

Standaert-Vitse, A., Sendid, B., Joossens, M., Francois, N., Vandewalle-El Khoury, P., Branche, J., et al. (2009). Candida albicans Colonization and ASCA in familial Crohn's Disease. Am. J. Gastroenterol. 104, 1745-1753. doi: 10.1038/ajg.2009.225

Steck, N., Hoffmann, M., Sava, I., Kim, S., Hahne, H., Schemann, M., et al. (2011). Enterococcus faecalis metalloprotease compromises epithelial barrier and contributes to intestinal inflammation. Int. J. Med. Microbiol. 301, 106-106. doi: $10.1053 /$ j.gastro.2011.05.035

Stepek, G., Auchie, M., Tate, R., Watson, K., Russell, D. G., Devaney, E., et al. (2002). Expression of the filarial nematode phosphorylcholinecontaining glycoprotein, ES62, is stage specific. Parasitology 125, 155-164. doi: $10.1017 /$ S0031182002001920

Strauss, J., Kaplan, G. G., Beck, P. L., Rioux, K., Panaccione, R., Devinney, R., et al. (2011). Invasive potential of gut mucosa-derived Fusobacterium nucleatum positively correlates with IBD status of the host. Inflamm. Bowel Dis. 17, 1971-1978. doi: 10.1002/ibd.21606

Summers, R. W., Elliott, D. E., Urban, J. F., Thompson, R., and Weinstock, J. V. (2005a). Trichuris suis therapy in Crohn's disease. Gut 54, 87-90 doi: 10.1136/gut.2004.041749

Summers, R. W., Elliott, D. E., Urban, J. F., Thompson, R. A., and Weinstock, J. V. (2005b). Trichuris suis therapy for active ulcerative colitis: a randomized controlled trial. Gastroenterology 128, 825-832. doi: 10.1053/j.gastro.2005.01.005

Tamboli, C. P., Neut, C., Desreumaux, P., and Colombel, J. F. (2004). Dysbiosis as a prerequisite for IBD. Gut 53, 1057. doi: 10.1136/gut.53.1.1

Turnbaugh, P. J., Baeckhed, F., Fulton, L., and Gordon, J. I. (2008). Diet-induced obesity is linked to marked but reversible alterations in the mouse distal gut microbiome. Cell Host Microbe 3, 213-223. doi: 10.1016/j.chom.2008.02.015

Turnbaugh, P. J., Hamady, M., Yatsunenko, T., Cantarel, B. L., Duncan, A., Ley, R. E., et al. (2009). A core gut microbiome in obese and lean twins. Nature 457, 480-484. doi: 10.1038/nature 07540

Turner, D., Levine, A., Kolho, K. L., Shaoul, R., and Ledder, O. (2014). Combination of oral antibiotics may be effective in severe pediatric ulcerative colitis: a preliminary report. J. Crohns Colitis 8, 1464-1470. doi: 10.1016/j.crohns.2014.05.010

Uhr, J. W., Dancis, J., Franklin, E. C., Finkelstein, M. S., and Lewis, E. W. (1962). The antibody response to bacteriophage phi-X 174 in newborn premature infants. J. Clin. Invest. 41, 1509-1513. doi: 10.1172/JCI104606

Underhill, D. M., and Iliev, I. D. (2014). The mycobiota: interactions between commensal fungi and the host immune system. Nat. Rev. Immunol. 14, 405-416. doi: 10.1038/nri3684

Varela, E., Manichanh, C., Gallart, M., Torrejón, A., Borruel, N., Casellas, F., et al. (2013). Colonisation by Faecalibacterium prausnitzii and maintenance of clinical remission in patients with ulcerative colitis. Aliment. Pharmacol. Ther. 38, 151-161. doi: 10.1111/apt.12365 
Velthuis, J. H., Unger, W. W., Abreu, J. R., Duinkerken, G., Franken, K., Peakman, $\mathrm{M}$, et al. (2010). Simultaneous detection of circulating autoreactive CD8(+) T-cells specific for different islet cell-associated epitopes using combinatorial MHC multimers. Diabetes 59, 1721-1730. doi: 10.2337/db09-1486

Virgin, H. W. (2014). The virome in mammalian physiology and disease. Cell 157, 142-150. doi: 10.1016/j.cell.2014.02.032

Vrieze, A., Van Nood, E., and Holleman, F. (2013). Transfer of intestinal microbiota from lean donors increases insulin sensitivity in individuals with metabolic syndrome (vol 143, pg 913, 2012). Gastroenterology 144, 250-250. doi: 10.1053/j.gastro.2012.11.032

Wagner, J., Maksimovic, J., Farries, G., Sim, W. H., Bishop, R. F., Cameron, D. J., et al. (2013). Bacteriophages in gut samples from pediatric Crohn's disease patients: metagenomic analysis using 454 pyrosequencing. Inflamm. Bowel Dis. 19, 1598-1608. doi: 10.1097/MIB.0b013e318292477c

Waller, A. S., Yamada, T., Kristensen, D. M., Kultima, J. R., Sunagawa, S., Koonin, E. V., et al. (2014). Classification and quantification of bacteriophage taxa in human gut metagenomes. ISME J. 8, 1391-1402. doi: 10.1038/ismej.2014.30

Wehkamp, J., Harder, J., Wehkamp, K. B., Wehkamp-von Meissner, B., Schlee, M., Enders, C., et al. (2004). NF-кB-and AP-1-mediated induction of human beta defensin-2 in intestinal epithelial cells by Escherichia coli Nissle 1917: a novel effect of a probiotic bacterium. Infect. Immun. 72, 5750-5758. doi: 10.1128/IAI.72.10.5750-5758.2004

Weinstock, J. V., and Elliott, D. E. (2009). Helminths and the IBD hygiene hypothesis. Inflamm. Bowel Dis. 15, 128-133. doi: 10.1002/ibd.20633

Weinstock, J. V., Summers, R. W., Elliott, D. E., Qadir, K., Urban, J. F., and Thompson, R. (2002). The possible link between de-worming and the emergence of immunological disease. J. Lab. Clin. Med. 139, 334-338. doi: $10.1067 / \mathrm{mlc} .2002 .124343$

Willing, B., Halfvarson, J., Dicksved, J., Rosenquist, M., Järnerot, G., Engstrand, L., et al. (2009). Twin studies reveal specific imbalances in the mucosa-associated microbiota of patients with ileal Crohn's disease. Inflamm. Bowel Dis. 15, 653-660. doi: 10.1002/ibd.20783

Wu, G. D., Chen, J., Hoffmann, C., Bittinger, K., Chen, Y. Y., Keilbaugh, S. A., et al. (2011). Linking long-term dietary patterns with gut microbial enterotypes. Science 334, 105-108. doi: 10.1126/science.1208344

Xenoulis, P. G., Palculict, B., Allenspach, K., Steiner, J. M., Van House, A. M., and Suchodolski, J. S. (2008). Molecular-phylogenetic characterization of microbial communities imbalances in the small intestine of dogs with inflammatory bowel disease. FEMS Microbiol. Ecol. 66, 579-589. doi: 10.1111/j.1574-6941.2008.00556.x

Yan, X., Sivignon, A., Yamakawa, N., Crepet, A., Travelet, C., Borsali, R., et al. (2015). Glycopolymers as antiadhesives of E. coli strains inducing inflammatory bowel diseases. Biomacromolecules 16, 1827-1836. doi: 10.1021/acs.biomac.5b00413

Yang, X. D., Yang, Y. P., Wang, Y. Y., Zhan, B., Gu, Y., Cheng, Y. L., et al. (2014)Excretory/secretory products from trichinella spiralis adult worms ameliorate DSS-induced colitis in mice. PLoS ONE 9:96454. doi: 10.1371/journal.pone.0096454

Yang, YJ., Kim, M.-S., Kim, E., Cheon, J. H., Lee, Y.-S., Choi, S. S., et al. (2016) Enteric viruses ameliorate gut inflammation via toll-like receptor 3 and tolllike receptor 7 -mediated interferon- $\beta$ production. Immunity 44, 889-900. doi: 10.1016/j.immuni.2016.03.009

Yatsunenko, T., Rey, F. E., Manary, M. J., Trehan, I., Dominguez-Bello, M. G., Contreras, M., et al. (2012). Human gut microbiome viewed across age and geography. Nature 486, 222-227. doi: 10.1038/nature11053

Yu, T., Guo, F., Yu, Y., Sun, T., Ma, D., Han, J., et al. (2017). Fusobacterium nucleatum promotes chemoresistance to colorectal cancer by modulating autophagy. Cell 170, 548-563.e16. doi: 10.1016/j.cell.2017. 07.008

Zhang, Y. F., and LeJeune, J. T. (2008). Transduction of bla(CMY-2), tet(A), and tet(B) from Salmonella enterica subspecies enterica serovar Heidelberg to S-Typhimurium. Vet. Microbiol. 129, 418-425. doi: 10.1016/j.vetmic.2007. 11.032

Zhu, W. H., Winter, M. G., Byndloss, M. X., Spiga, L., Duerkop, B. A., Hughes, E. R., et al. (2018). Precision editing of the gut microbiota ameliorates colitis. Nature 553, 208-211. doi: 10.1038/nature25172

Zuo, T., Kamm, M. A., Colombel, J.-F., and Ng, S. C. (2018). Urbanization and the gut microbiota in health and inflammatory bowel disease. Nat. Rev. Gastro. Hepat. 15:440-452. doi: 10.1038/s41575-018-0003-z.

Zuo, T., Wong, S. H., Lam, L. Y. K., Lui, R., Cheung, K., Tang, W., et al. (2017). Bacteriophage transfer during fecal microbiota transplantation is associated with treatment response in clostridium difficile infection. Gastroenterology 152, S140-S141. doi: 10.1016/S0016-5085(17)30798-9

Conflict of Interest Statement: The authors declare that the research was conducted in the absence of any commercial or financial relationships that could be construed as a potential conflict of interest.

Copyright (c) $2018 \mathrm{Zuo}$ and $\mathrm{Ng}$. This is an open-access article distributed under the terms of the Creative Commons Attribution License (CC BY). The use, distribution or reproduction in other forums is permitted, provided the original author(s) and the copyright owner(s) are credited and that the original publication in this journal is cited, in accordance with accepted academic practice. No use, distribution or reproduction is permitted which does not comply with these terms. 